\title{
Разработка методики анализа летучих органических соединений в почве с использованием портативного хроматографа на основе микрофлюидных систем
}

\author{
Платонов И.А. ${ }^{1}$, Платонов Вл.И. ${ }^{1}$, Платонов Вал.И. ${ }^{1}$, Ворон С.В. ${ }^{2}$ \\ ${ }^{1}$ Самарский национальный исследовательский университет имени академика С.П. Королева, Самара \\ ${ }^{2}$ ФББУ СЭУ ФПС ИПЛ по Самарской области, Самара
}

Поступила в редакцию 23.01.2019 г.

DOI: https://doi.org/10.17308/sorpchrom.2019.19/734

В статье представлена реализация методики качественного и количественного анализа летучих органических соединений в почве при помощи портативного газового хроматографа на основе микрофлюидных систем. Показано что при использовании парофазного анализа и портативного газового хроматографа на основе микрофлюидных систем возможно за 120 секунд с чувствительностью до $2 \times 10^{-2}$ мг/кг (по бензолу) определять качественный и количественный состав смеси алифатических и непредельных углеводородов, находящихся в почве, как в лабораторных, таки в полевых условиях.

Ключевые слова: газовая хроматография, микрофлюидные системы, парофазный анализ.

\section{Development of methods for the analysis of volatile organic compounds in the soil using a portable chromatograph based on microfluidic systems}

\author{
Platonov I.A. ${ }^{1}$, Platonov V1.I. ${ }^{1}$, Platonov Val.I. ${ }^{1}$, Voron S.V. ${ }^{2}$ \\ ${ }^{1}$ Samara University, Samara \\ ${ }^{2}$ FSBI SEP FPS IPL in the Samara region, Samara
}

\begin{abstract}
Examination of the content of volatile organic compounds in the soil is a trivial task solved by modern laboratory analysis mainly by chromatographic methods (gas chromatography (GC), high performance liquid chromatography (HPLC), thin layer chromatography (TLC)) by hybrid methods (GC and HPLC with mass-selective detection ) [1]. However, there are tasks of analytical chemistry that are problematic to solve with existing laboratory methods. Such tasks include the analysis of trace amounts of VOCs in the soil during the examination of fires. Often, the ratio of organic substances contained in a sample after its selection, transportation and preparation changes prior to analysis, which greatly complicates the interpretation of analysis results. This makes actual the development of devices and VOC methods in the soil, which allow accurate and highly sensitive component analysis of organic compounds in the field.

The article presents the implementation of the methodology for the qualitative and quantitative analysis of volatile organic compounds in the soil using a portable gas chromatograph based on microfluidic systems. It is shown that when using vapor-phase analysis and a portable gas chromatograph based on microfluidic systems (weight $-1.5 \mathrm{~kg}$, dimensions - $220 \times 145 \times 55 \mathrm{~mm}$ ), allows to provide time of the analysis is 120 seconds, sensitivity is $2 \times 10^{-2} \mathrm{mg} / \mathrm{kg}$ (benzene ) when determining the qualitative and quantitative composition of the mixture of aliphatic and unsaturated hydrocarbons in the soil. A significant reduction in the mass-dimensional characteristics of the device is due to the use in its design of microfluidic systems for dosing and chromatographic separation of the sample being analyzed [2].
\end{abstract}

Keywords: gas chromatography, microfluidic systems, headspace analysis. 


\section{Введение}

Экспертиза содержания летучих органических соединений в почве является тривиальной задачей, решаемой современным лабораторным анализом главным образом хроматографическими методами (газовой хроматографией $(\Gamma \mathrm{X})$, высокоэффективной жидкостной хроматографией (ВЭЖХ), тонкослойной хроматографией (ТСХ)) гибридными методами (ГХ и ВЭЖХ с масс-селективным детектированием) [1]. Однако существуют задачи аналитической химии, которые проблемно решить существующими лабораторными методами. К таким задачам можно отнести анализ следовых количеств ЛОС в почве при экспертизе пожаров. Зачастую соотношение органических веществ, содержащихся в пробе, после ее отбора, транспортировки и подготовки перед анализом видоизменяется, что значительно усложняет интерпретацию результатов анализа. Это делает актуальным разработку устройств и методов ЛОС в почве, позволяющих точно и с высокой чувствительностью проводить компонентный анализ органических соединений в полевых условиях.

Целью данной работы являлась разработка портативного газового хроматографа на основе микрофлюидных систем для анализа ЛОС в почве. Для реализации представленной цели необходимо было разработать газохроматографическую систему на основе микрофлюидных систем, позволяющую эффективно дозировать, хроматографически разделять и детектировать ЛОС в почве, разработать методику анализа и подготовки проб, обеспечивающую высокую чувствительность и качественную идентификацию компонентов смеси.

\section{Эксперимент}

Парофазнный анализ относится к одному из самых популярных методов определения загрязняющих веществ в почве. Он прост, быстр, дешев и обладает хорошими метрологическими характеристиками, в том числе и низким пределом обнаружения [3]. Он широко применяется для газохроматографического анализа летучих органических соединений в почве[4-6]. В рамках реализации представленного проекта был создан простейший термодесорбер для стеклянных пузырьков объемом $1.5 \mathrm{~cm}^{3}$ (рис. 1), представляющий собой трубчатую печь с внутренним диаметром 10 мм. Один грамм пробы помещался в стеклянный пузырек, который герметично закрывался и помещался в термодесорбер. После экспонирования пузырька с пробой в течении 300 сек в термодесорбере при температуре $150^{\circ} \mathrm{C}$, при помощи одноразового шприца отбирался $1 \mathrm{~cm}^{3}$ паровой шапки над образцом отбирался и вводился в дозирующее устройство хроматографа.

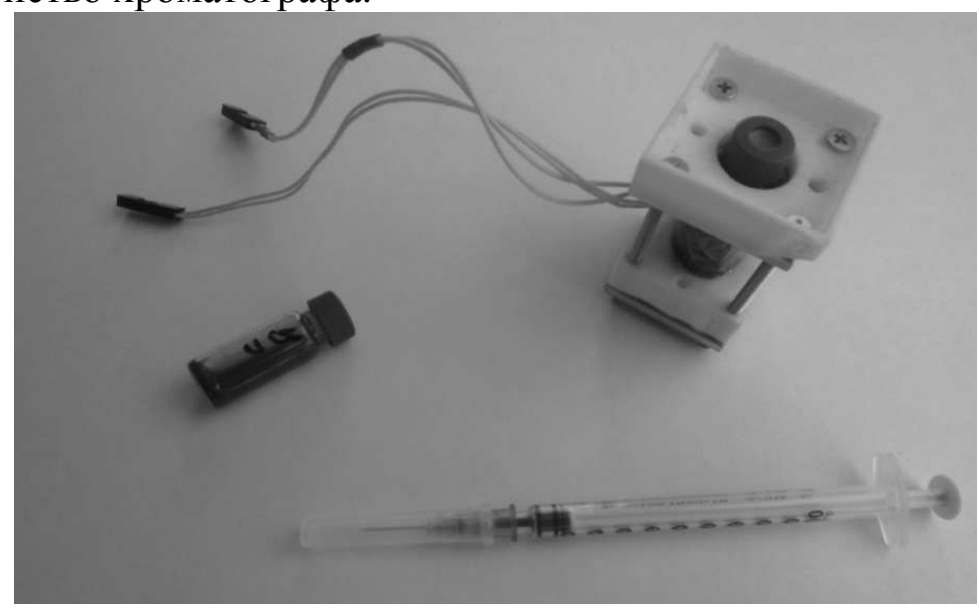

Рис. 1. Фотография термодесорбера. 
В качестве исследуемых проб использовался песок смоченный смесью алифатических и непредельных углеводородов (состав смеси углеводородов представлен в таблице 1), исследовались образцы, содержащие 0.1, 0.5 и 1.0 мкл смеси на 1 г песка.

Газохроматографический эксперимент проводился на портативном газовом хроматографе ПИА, схема и фотография которого представлены на рис. 2. Масса прибора вместе с термодесорбером составила 0.95 кг, в качестве разделительной хроматографической колонки использовала планарная микрохроматографическая колонка длиной 1.2 м и сечением $0.7 \times 0.7$ мм, заполненная сорбентом Триспропионитрил)амин (10\% масс) на Инзенском кирпиче (0.125-0.16 мм). В качестве газа-носителя использовался очищенный воздух (давление -150 Кпа, расход $8.6 \mathrm{~cm}^{3} /$ мин), объем дозирующей петли - 100 мкл, детектор - микротермохимический.

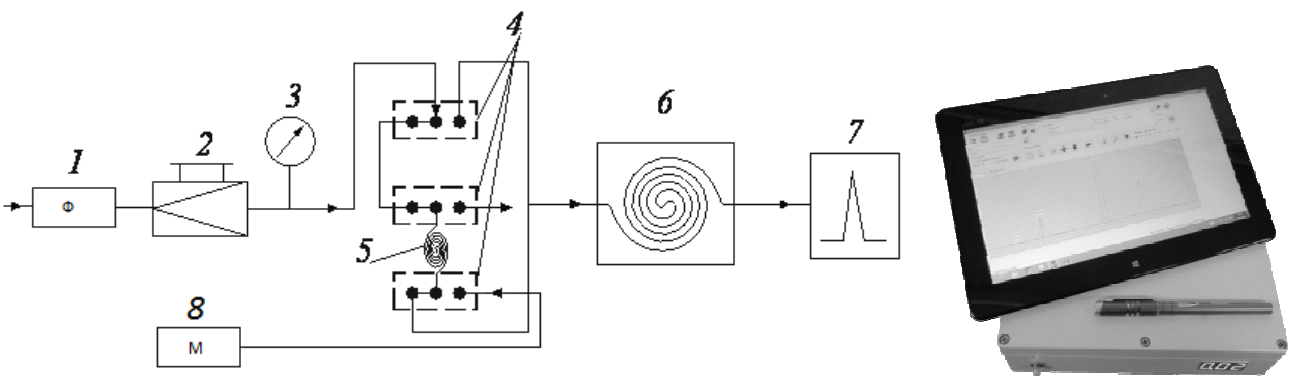

Рис. 2. Схема и фотография газового хроматографа на снове микрофлюидных систем с термодесорбером. 1 - фильтр, 2 - редуктор , 3 - маноментр ,4 - три электромагнитных клапана, 5 - дозирующая петля, 6 - микрохроматографическая колонка на плоскости, 7 - микротермохимический детектор, 8- термодесорбер.

Чувствительность приставленного комплекса по отношению к углеводородам рассчитывали по формуле:

$$
c_{\min }=\frac{3 \cdot \Delta_{x} \cdot m}{\bar{S} \cdot m_{\text {общ }}}
$$

где $\mathrm{m}$ - масса контрольного компонента, мг; $\overline{\mathbf{s}}$ - среднее арифметическое значение площади пика, мB c; $\mathrm{m}_{\text {общ }}$ - масса субстрата, кг.

\section{Эксперимент}

На рис. 3 представлена хроматограмма разделения смеси алифатических и непредельных углеводородов при помощи разработанного комплекса.

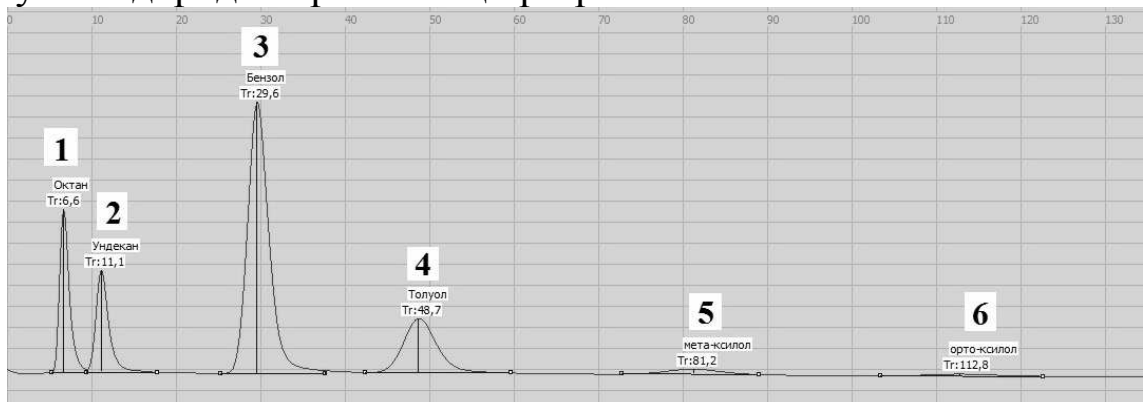

Рис. 3. Хроматограмма разделения смеси алифатических и непредельных углеводородов, полученная при помощи представленного комплекса. Температура дозирующего устройства и колонки составляла 80С, давление газа-носителя (воздуха) - 150 кПа, сорбаты: 1) $н$-октан; 2) $н$-ундекан; 3) бензол; 4) толуол; 5) мета-ксилол; 6) орто-ксилол. 
При помощи изготовленного комплекса были проведены пять последовательных измерений трех образцов песка, содержащих $0.1,0.5$ и 1.0 мкл/г смеси углеводородов. Результаты эксперимента представлены в таблице 1.

Таблица 1. Результаты пяти последовательных измерений трех образцов песка, содержащих $0.1,0.5$ и 1.0 мкл/г смеси углеводородов.

\begin{tabular}{|c|c|c|c|}
\hline \multirow{2}{*}{ Компонент } & \multicolumn{3}{|c|}{ Среднее значение площадей хроматографических пиков и СКО, мВ/сек } \\
\cline { 2 - 4 } & 0.1 & 0.5 & 1.0 \\
\hline & $11.60 \pm 0.93$ & $53.92 \pm 2.70$ & $86.38 \pm 2.59$ \\
\hline Октан & $6.01 \pm 0.60$ & $20.26 \pm 1.62$ & $37.74 \pm 1.51$ \\
\hline Ундекан & $45.17 \pm 0.90$ & $223.41 \pm 4.47$ & $385.29 \pm 11.56$ \\
\hline Бензол & $12.80 \pm 0.90$ & $50.08 \pm 4.01$ & $88.43 \pm 8.84$ \\
\hline Толуол & $1.72 \pm 0.21$ & $7.27 \pm 0.73$ & $10.49 \pm 0.63$ \\
\hline Мета-ксилол & $0.85 \pm 0.10$ & $4.27 \pm 0.38$ & $7.23 \pm 0.58$ \\
\hline Орто-ксилол & $78.15 \pm 3.64$ & $359.19 \pm 13.90$ & $615.55 \pm 25.71$ \\
\hline $\begin{array}{c}\text { Сумма } \\
\text { площадей } \\
\text { компонентов }\end{array}$ & & & \\
\hline
\end{tabular}

Как видно из данных, представленных в таблице 3, максимальное СКО не превышало $12 \%$ и наблюдалось для хроматографических пиков, отвечающих за наличие в смеси орто-ксилола (для концентрации 0.1 мкл/г). На рисунке 4 представлена градировочная зависимость суммы площадей компонентов от концентрации смеси в песке.

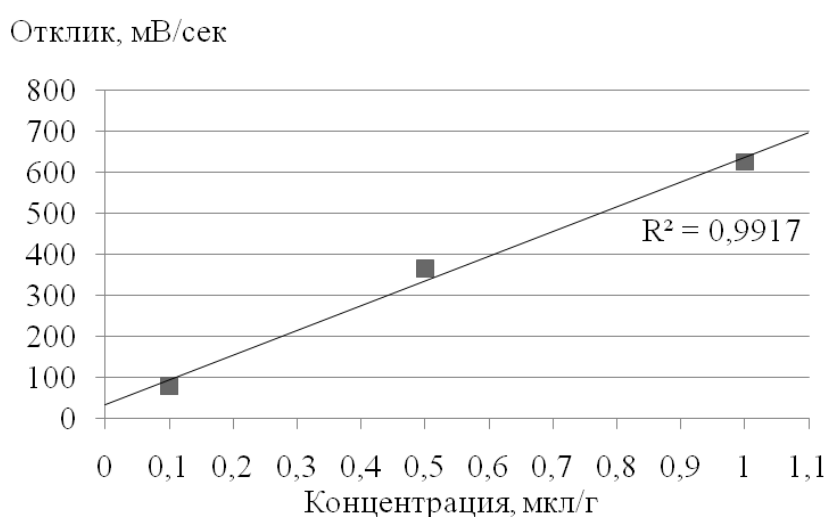

Рис. 4. Градировочная зависимость суммы площадей компонентов от концентрации смеси углеводородов в песке.

Как видно величина достоверности аппроксимации составила 0.99. По формуле 1 , была рассчитана чувствительность изготовленной газохроматографической системы по отношению ко всем исследуемым углеводородам, результаты расчёта представлены в таблице 2.

Таблица 2. Чувствительность изготовленной газохроматографической системы по отношению к исследуемым углеводородам

\begin{tabular}{|c|c|c|c|c|}
\hline Компонент & $\begin{array}{c}\text { Концентрация, } \\
\text { мг/кг }\end{array}$ & $\begin{array}{c}\text { Отклик, } \\
\text { мВ/сек }\end{array}$ & $\begin{array}{c}\text { Шум, } \\
\mathrm{MB}\end{array}$ & $\begin{array}{c}\text { Чувствительность, } \\
\text { мг/кг }\end{array}$ \\
\hline 1 & 2 & 3 & 4 & 5 \\
\hline Октан & 15 & 11.60 & & 0.019 \\
\hline Ундекан & 7 & 6.01 & 0.005 & 0.017 \\
\cline { 1 - 2 } & 60 & 45.17 & & 0.020 \\
\hline
\end{tabular}




\begin{tabular}{|c|c|c|c|c|}
\hline 1 & 2 & 3 & 4 & 5 \\
\hline Толуол & 15 & 12.80 & & 0.018 \\
\hline Мета-ксилол & 2 & 1.72 & \multirow{2}{*}{0.005} & 0.017 \\
\hline Орто-ксилол & 1 & 0.85 & & 0.018 \\
\cline { 1 - 2 } $\begin{array}{c}\text { Сумма } \\
\text { компонентов }\end{array}$ & 100 & 78.15 & & 0.019 \\
\hline
\end{tabular}

Как видно из таблицы 4 среднее значение чувствительности составило 0.018 мг/кг, что на порядок ниже нежели ПДК содержания исследуемых углеводородов в почве, что делает возможным применение созданого комплекса не только в криминалистике, но и при экологическом мониторинге.

\section{Заключение}

В результате исследования был разработан газохроматографический комплекс весом менее одного килограмма, позволяющий экспрессно (время одного цикла анализа менее 2-х минут), с высокой чувствительностью (до 0.018 мг/кг), проводить качественный и количественный анализ углеводородов в почве. Разработанный комплекс позволит экспрессно и надежно проводить анализ ЛОС в почве, как в лабораторных, так и в полевых условиях.

Работа выполнена при финансовой поддержке

Российского фонда фундаментальных исследований (проект № 17-43-630873). This work was financially supported by the Russian Foundation for Basic Research (Project No. 17-43-630873).

\section{Список литературы}

1. Другов Ю.С., Родин А.А. Анализ загрязненной почвы и опасных отходов. М. Бином 2007. $424 \mathrm{c}$.

2. Platonov I.A., Platonov V.I., Goryunov M.G. Journal of Analytical Chemistry. 2015. Vol. 70. No 9. pp. 1158-11635.

3. Сониясси Р., Сандра П., Шлетт К. Анализ воды: органические микропримеси. Практическое руководство. Санкт Питербург: ТЕЗА. 200. С. 250.

\section{References}

1. Drugov Yu.S., Rodin A.A., Analysis of contaminated soil and hazardous waste, M., Bean, 2007. 424 p.

2. Platonov I.A., Platonov V.I., Goryunov M.G., Journal of Analytical Chemistry, 2015, Vol. 70, No 9, pp. 1158-11635.

3. Soniassi R., Sandra P., Schlett K. Water Analysis: Organic Traces. A practical guide. St. Petersburg. TEZA, 200, p. 250.

Платонов Игорь Артемьевич - д.т.н., профессор кафедры химии Самарского Университета, Самара.
4. Psillakis E. Analytica Chimica Acta. 2017. Vol. 986. pp. 12-24.

5. Raza N., Hashemi B., Kim K., Lee S., Deep A. Trends in Analytical Chemistry, 2018, Vol. 103. pp. 56-73.

6. Soria A.C., García-Sarrió M.J., Sanz M.L. Trends in Analytical Chemistry. 2015. Vol. 71. pp. 85-99.

4. Psillakis E., Analytica Chimica Acta, 2017, Vol. 986, pp. 12-24.

5. Raza N., Hashemi B., Kim K., Lee S., Deep A. Trends in Analytical Chemistry, 2018, Vol. 103, pp. 56-73.

6. Soria A.C., García-Sarrió M.J., Sanz M.L. Trends in Analytical Chemistry, 2015, Vol. 71, pp. 85-99.

Platonov Igor A. - grand Ph.d (Technical science), Prof., Department of Chemistry, Samara University, Samara. 
Платонов Владимир Игоревич - к.Х.н., доцент кафедры химии Самарского Университета, Самара.

Платонов Валерий Игоревич - аспирант кафедры химии Самарского Университета, Самаpa.

Ворон Сергей Владимирович - эксперт ФГБУ СЭУ ФПС ИПЛ по Самарской области, Самара.
Platonov Vladimir I. - Ph.D., Associate Professor, Department of Chemistry, Samara University, Samara.

Platonov Valeriy I. - postgraduate student, Department of Chemistry, Samara University, Samara.

Voron Sergey V. - expert of FGBU SEA FPS IPL in Samara Region, Samara. 